\author{
Associate Professor Hsiao-Fen HSIAO \\ E-mail: xiaoxiaofen@nbs.edu.cn \\ New Huadu Business School of Minjiang University, China \\ Bachelor Chunying XIA \\ E-mail: xiachunying8@163.com \\ Newhuadu Business School of Minjiang University, China \\ Associate Professor Serhat YÜKSEL \\ E-mail: serhatyuksel@medipol.edu.tr \\ The School of Business, İstanbul Medipol University, Turkey \\ Professor Hasan DINÇER \\ E-mail: hdincer@medipol.edu.tr \\ The School of Business, İstanbul Medipol University, Turkey
}

\title{
COMPARATIVE ANALYSIS OF INVESTOR SENTIMENT WITH WEATHER CONDITIONS USING INTERVAL TYPE 2 FUZZY HYBRID DECISION MAKING AND REGRESSION METHODS: EVIDENCE FROM CHINESE STOCK MARKETS
}

\begin{abstract}
This study investigates the local weather effects on investor sentiment as well as returns in the China's stock market. For this purpose, a comparative evaluation is performed by making both econometric analysis and fuzzy logic-based examination. In the first stage, in the second stage, interval type 2 (IT2) fuzzy DEMATEL and TOPSIS methods are used respectively for evaluating the performance of stock markets in the selected provinces of China. On the other side, linear regression analysis is made to reach this objective. In this framework, stock returns of China A-shares for the period of 1 January 2011 - 31 December 2017 are taken into consideration. The results of these two different analyses are quite consistent. The findings indicate that investors feel more optimistic about stocks and are more inclined to invest when sunlight is stronger. In addition to this issue, it is also concluded that investors are more inclined to invest in local stocks because of home bias and this situation leads to increase in the local stock market returns. Therefore, in bad weather, it would be appropriate to receive incentives to facilitate investors to trade on the stock exchange. For example, it is important to take measures to reduce the problems of investors' motivation, such as inaccessibility of session rooms and slow delivery of orders.

Keywords: Stock Markets; Investor Sentiment, Weather Conditions;

Transaction Behavior; Interval Type 2 Fuzzy Sets; DEMATEL; TOPSIS.
\end{abstract}

JEL Classification:G21, M52, P33

DOI: $10.24818 / 18423264 / 54.3 .20 .16$ 
Hsiao-Fen Hsiao, Chunying Xia, Serhat Yüksel, Hasan Dinçer

\section{Introduction}

Weather is an important environmental factor on which human beings depend for survival and development. It greatly affects and restricts human activities. However, human beings continue to be affected by the weather of their surroundings. Human beings become optimistic, cheerful, and confident during sunny days and become pessimistic and negative during gloomy days. Investors consider rational economic factors when making investment decisions but are also driven by subjective emotions in making decisions. The consequences of this emotionalization are eventually reflected in the capital market. Therefore, the capital market will also be affected by investor sentiment (Hill and Viceisza, 2012).

In particular, although China's stock market has developed late, there are several investors. According to the statistics of the China Securities Regulatory Commission, as of March 2019, there are more than 150 million investors in the Chinese stock market, of which small and medium-sized investors are the majority, accounting for more than $75 \%$ of the investors and their proportion of shares is over $50 \%$ (Wen et al., 2019). Compared with institutional investors who focus on fundamental value analysis, small and medium investors, who prefer technical speculation, are more susceptible to subjective mood swings. Therefore, studying investor sentiment and the generation and performance of various irrational behaviors is of great significance for formulating relevant policies, protecting the rights of small and medium-sized investors, strengthening the investor protection system, and ensuring the healthy development of the capital market during the economic transition period in China (Hou et al., 2019).

As the national economy's barometer, the stock market plays an important role in its stability and development. As a result of immature market economy mechanisms in China, several market anomalies such as the Sunday effect and the month effect exist in the Chinese stock market, making a series of market signals such as stock prices and dividend policy dysfunctional to some extent. Traditional financial theory, which is based on the assumption of an economic man, cannot fully interpret the relation between aggregate stock return performance and investor behavior solely on the basis of traditional economic factors because they cannot explain stock market anomalies (Abbas et al., 2019).

Irrational investors, whose trading strategies are based on psychological factors like mood and emotion, also have an impact on aggregate stock market performance (Shi et al., 2019). In recent years, behavioral finance has emerged as a new approach to interpret market anomalies, with the development of financial theories (Wei et al., 2019). Psychological evidence suggests that factors such as light, air quality, and the human body clock have an effect on investor sentiment. This paper explores the impact of sunshine, which is an important weather phenomenon, on the stock returns of core cities in China (Chen, 2019). 
Comparative Analysis of Investor Sentiment with Weather Conditions Using Interval Type 2 Fuzzy Hybrid Decision Making and Regression Methods: Evidence from Chinese Stock Markets

In this study, it is aimed to evaluate the local weather effects on investor sentiment and stock market growth. In order to reach this objective, a comparative evaluation is performed by making both econometric analysis and fuzzy logicbased examination. In the first stage, linear regression analysis is made whereas IT2 fuzzy DEMATEL and TOPSIS methods are used respectively for evaluating the performance of stock markets in the selected provinces of China in the second stage. To make up for this shortcoming, data from five core cities, Beijing, Shanghai, Shenzhen, Hangzhou, and Suzhou, has been considered in this paper to explore the impact of local weather, especially natural light, on stock returns from a geographic perspective. These five cities are located throughout the country and are economically developed. They rank among the top cities in the world in terms of the number of listed companies, market value, transaction amount, and number of business outlets. Furthermore, they are important because they represent the Chinese stock market.

Therefore, it is possible to say that there are three main hypotheses in this study. The first hypothesis is that there is a negative correlation between cloudy skies and stock returns. In other words, the company's stock returns will be greater in case of the fact that the cloud coverage is lighter. While looking at this hypothesis, it can be understood that geographical factors do influence investors' decision-making. In addition to this issue, the second hypothesis is that there is a negative correlation between cloud coverage and stock returns in different cities. On the other side, the final hypothesis indicates that the weather's influence on companies' stock returns varies depending on the company's characteristics. That is to say, specifically, small, volatile, profit-thin companies are more sensitive to the weather's influence.

There are many different novelties of this study. In the first aspect, five core cities of China (Beijing, Shanghai, Shenzhen, Hangzhou, and Suzhou) has been firstly considered in this paper with respect to the impact of weather conditions on stock market performance. In addition to this situation, another important novelty of this study is considering both econometric and fuzzy logicbased analyses together. By making econometric analysis, it is possible to understand the relationship with the help of numerical values. On the other side, fuzzy multi-criteria methods give also significant results under uncertain conditions. For instance, fuzzy DEMATEL approach is mainly preferred to weight different factors and create impact relation map between them. On the other hand, TOPSIS methodology is used to rank different alternatives. Additionally, with respect to the fuzzy logic, expert opinions are taken into consideration. Hence, it is believed that using both numerical values and expert opinions has an increasing effect on the originality of this study.

This study consists of five chapters. In this introduction, which is the first part, general concepts related to the subject are discussed. The second part includes literature review. In this section, the studies are divided into three different parts.

DOI: $10.24818 / 18423264 / 54.3 .20 .16$ 
Firstly, studies on the effect of weather on stock exchanges are discussed. Subsequently, studies on the concept of localized trading tendency were considered. In the last part of the literature review, studies taking into account the methods used in the study are included. In the third part of the study, the theoretical background of the methods used in the analysis is explained. On the other hand, in the fourth part of the study, analysis results are shared. In the last section, the findings are given. In this section, the findings are compared with the studies in the literature.

\section{Methodology}

Two different analyses are performed in this study. Firstly, IT2 fuzzy DEMATEL and TOPSIS methods are considered to see the impact of local weather on the return rates of local stock markets. In the second step, linear regression methodology is used for the same purpose. In this title, these three methods are explained.

Decision making trial and evaluation laboratory entitled DEMATEL is firstly used by Geneva Research Centre of the Battelle Memorial Institute to figure out the degrees and direction of mutual relationship between factors (Jeng and Tzeng, 2012; Patil and Kant, 2014). IT2 fuzzy sets is the generalization of fuzzy sets by considering the upper and lower membership functions at the same time. $\tilde{A}$ is the type 2 fuzzy set and the membership function is $\mu_{\tilde{A}(x, u)}, x \in X$ and $u \in J_{x} \subseteq$ [0,1] (Mendel et al. 2006).

$\tilde{A}=\left\{\left((x, u), \mu_{\tilde{A}(x, u)}\right) \mid \forall_{x} \in X, \forall_{u} \in J_{x} \subseteq[0,1]\right\}$, or $\tilde{A}=\int_{x \in X} \int_{u \in J_{x}} \frac{\mu_{\tilde{A}}(x, u)}{(x, u)} J_{x} \subseteq[0,1]$

Where $\iint$ is the union over all admissible $x$ and $u$ and $\mu_{\tilde{A}}(x, u)$ are limited between 0 and 1 . $\int$ is presented by $\Sigma$ for discrete universes of discourse. When the value of $\mu_{\tilde{A}}(x, u)$ is $1, \tilde{A}$ is given as

$$
\tilde{A}=\int_{x \in X} \int_{u \in J_{x}} \frac{1}{(x, u)} J_{x} \subseteq[0,1]
$$

$\tilde{A}_{i}^{U}$ is the upper trapezoidal membership function and $\tilde{A}_{i}^{L}$ is the lower trapezoidal membership function. The function is detailed as follows

$\tilde{A}_{i}=\left(\tilde{A}_{i}^{U}, \tilde{A}_{i}^{L}\right)=\left(\left(a_{i 1}^{U}, a_{i 2}^{U}, a_{i 3}^{U}, a_{i 4}^{U} ; H_{1}\left(\tilde{A}_{i}^{U}\right), H_{2}\left(\tilde{A}_{i}^{U}\right)\right),\left(a_{i 1}^{L}, a_{i 2}^{L}, a_{i 3}^{L}, a_{i 4}^{L} ; H_{1}\left(\tilde{A}_{i}^{L}\right), H_{2}\left(\tilde{A}_{i}^{L}\right)\right)\right)$

Where $a_{i 1}^{U}, a_{i 2}^{U}, a_{i 3}^{U}, a_{i 4}^{U}, a_{i 1}^{L}, a_{i 2}^{L}, a_{i 3}^{L}, a_{i 4}^{L}$ are the reference values of $\tilde{A}_{i}$. $H_{j}\left(\tilde{A}_{i}^{U}\right)$ is the membership value of the element $a_{i(j+1)}^{U}$. The value of $\mathrm{j}$ is between 1 and 2. However, the essentials of the IT2 fuzzy sets are given in the following formulas 
Comparative Analysis of Investor Sentiment with Weather Conditions Using Interval Type 2 Fuzzy Hybrid Decision Making and Regression Methods: Evidence from Chinese Stock Markets

$$
\begin{aligned}
& \tilde{A}_{1} \oplus \tilde{A}_{2}=\left(\tilde{A}_{1}^{U}, \tilde{A}_{1}^{L}\right) \oplus\left(\tilde{A}_{2}^{U}, \tilde{A}_{2}^{L}\right) \\
& =\left(\left(a_{11}^{U}+a_{21}^{U}, a_{12}^{U}+a_{22}^{U}, a_{13}^{U}+a_{23}^{U}, a_{14}^{U}\right.\right. \\
& \left.+a_{24}^{U} ; \min \left(H_{1}\left(\tilde{A}_{1}^{U}\right), H_{1}\left(\tilde{A}_{2}^{U}\right)\right), \min \left(H_{2}\left(\tilde{A}_{1}^{U}\right), H_{2}\left(\tilde{A}_{2}^{U}\right)\right)\right),\left(a_{11}^{L}\right. \\
& +a_{21}^{L}, a_{12}^{L}+a_{22}^{L}, a_{13}^{L}+a_{23}^{L}, a_{14}^{L} \\
& \left.\left.+a_{24}^{L} ; \min \left(H_{1}\left(\tilde{A}_{1}^{L}\right), H_{1}\left(\tilde{A}_{2}^{L}\right)\right), \min \left(H_{2}\left(\tilde{A}_{1}^{L}\right), H_{2}\left(\tilde{A}_{2}^{L}\right)\right)\right)\right)(4) \\
& \tilde{A}_{1} \ominus \tilde{A}_{2}=\left(\tilde{A}_{1}^{U}, \tilde{A}_{1}^{L}\right) \ominus\left(\tilde{A}_{2}^{U}, \tilde{A}_{2}^{L}\right) \\
& =\left(\left(a_{11}^{U}-a_{24}^{U}, a_{12}^{U}-a_{23}^{U}, a_{13}^{U}-a_{22}^{U}, a_{14}^{U}\right.\right. \\
& \left.-a_{21}^{U} ; \min \left(H_{1}\left(\tilde{A}_{1}^{U}\right), H_{1}\left(\tilde{A}_{2}^{U}\right)\right), \min \left(H_{2}\left(\tilde{A}_{1}^{U}\right), H_{2}\left(\tilde{A}_{2}^{U}\right)\right)\right),\left(a_{11}^{L}\right. \\
& -a_{24}^{L}, a_{12}^{L}-a_{23}^{L}, a_{13}^{L}-a_{22}^{L}, a_{14}^{L} \\
& \left.\left.-a_{21}^{L} ; \min \left(H_{1}\left(\tilde{A}_{1}^{L}\right), H_{1}\left(\tilde{A}_{2}^{L}\right)\right), \min \left(H_{2}\left(\tilde{A}_{1}^{L}\right), H_{2}\left(\tilde{A}_{2}^{L}\right)\right)\right)\right)(5) \\
& \tilde{A}_{1} \otimes \tilde{A}_{2}=\left(\tilde{A}_{1}^{U}, \tilde{A}_{1}^{L}\right) \otimes\left(\tilde{A}_{2}^{U}, \tilde{A}_{2}^{L}\right) \\
& =\left(\left(a_{11}^{U} \times a_{21}^{U}, a_{12}^{U} \times a_{22}^{U}, a_{13}^{U} \times a_{23}^{U}, a_{14}^{U}\right.\right. \\
& \left.\times a_{24}^{U} ; \min \left(H_{1}\left(\tilde{A}_{1}^{U}\right), H_{1}\left(\tilde{A}_{2}^{U}\right)\right), \min \left(H_{2}\left(\tilde{A}_{1}^{U}\right), H_{2}\left(\tilde{A}_{2}^{U}\right)\right)\right),\left(a_{11}^{L}\right. \\
& \times a_{21}^{L}, a_{12}^{L} \times a_{22}^{L}, a_{13}^{L} \times a_{23}^{L}, a_{14}^{L} \\
& \left.\left.\times a_{24}^{L} ; \min \left(H_{1}\left(\tilde{A}_{1}^{L}\right), H_{1}\left(\tilde{A}_{2}^{L}\right)\right), \min \left(H_{2}\left(\tilde{A}_{1}^{L}\right), H_{2}\left(\tilde{A}_{2}^{L}\right)\right)\right)\right)(6) \\
& k \tilde{A}_{1}=\left(k \times a_{11}^{U}, k \times a_{12}^{U}, k \times a_{13}^{U}, k\right. \\
& \left.\times a_{14}^{U} ; H_{1}\left(\tilde{A}_{1}^{U}\right), H_{2}\left(\tilde{A}_{1}^{U}\right)\right),\left(k \times a_{11}^{L}, k \times a_{12}^{L}, k \times a_{13}^{L}, k\right. \\
& \left.\times a_{14}^{L} ; H_{1}\left(\tilde{A}_{1}^{L}\right), H_{2}\left(\tilde{A}_{1}^{L}\right)\right) \\
& \frac{\tilde{A}_{1}}{k}=\left(\frac{1}{k} \times a_{11}^{U}, \frac{1}{k} \times a_{12}^{U}, \frac{1}{k} \times a_{13}^{U}, \frac{1}{k} \times a_{14}^{U} ; H_{1}\left(\tilde{A}_{1}^{U}\right), H_{2}\left(\tilde{A}_{1}^{U}\right)\right),\left(\frac{1}{k} \times a_{11}^{L}, \frac{1}{k} \times a_{12}^{L}, \frac{1}{k}\right. \\
& \left.\times a_{13}^{L}, \frac{1}{k} \times a_{14}^{L} ; H_{1}\left(\tilde{A}_{1}^{L}\right), H_{2}\left(\tilde{A}_{1}^{L}\right)\right)
\end{aligned}
$$

The steps of the modified DEMATEL are illustrated as follows (Baykasoglu and Golcuk, 2017). The first step is to define the direct relation matrix. The matrix $\tilde{Z}$ in the trapezoidal fuzzy form is given as $\tilde{Z}_{i j}=$

\section{DOI: $10.24818 / 18423264 / 54.3 .20 .16$}


Hsiao-Fen Hsiao, Chunying Xia, Serhat Yüksel, Hasan Dinçer

$\left(a_{i j}, b_{i j}, c_{i j}, d_{i j} ; H_{1}\left(z_{i j}^{U}\right), H_{2}\left(z_{i j}^{U}\right)\right),\left(e_{i j}, f_{i j}, g_{i j}, h_{i j} ; H_{1}\left(z_{i j}^{L}\right), H_{2}\left(z_{i j}^{L}\right)\right)$ and the matrix is illustrated in the following equation.

$\tilde{Z}=\left[\begin{array}{ccccc}0 & \tilde{z}_{12} & \cdots & \cdots & \tilde{z}_{1 n} \\ \tilde{z}_{21} & 0 & \cdots & \cdots & \tilde{z}_{2 n} \\ \vdots & \vdots & \ddots & \cdots & \cdots \\ \vdots & \vdots & \vdots & \ddots & \vdots \\ \tilde{z}_{n 1} & \tilde{z}_{n 2} & \cdots & \cdots & 0\end{array}\right]$
$\tilde{Z}=\frac{\tilde{Z}^{1}+\tilde{Z}^{2}+\tilde{Z}^{3}+\cdots \tilde{Z}^{n}}{n}$

Next step is to apply the normalization procedure for the matrix as

$$
\begin{aligned}
& \tilde{X}=\left[\begin{array}{ccccc}
\tilde{x}_{11} & \tilde{x}_{12} & \cdots & \cdots & \tilde{x}_{1 n} \\
\tilde{x}_{21} & \tilde{x}_{22} & \cdots & \cdots & \tilde{x}_{2 n} \\
\vdots & \vdots & \ddots & \cdots & \cdots \\
\vdots & \vdots & \vdots & \ddots & \vdots \\
\tilde{x}_{n 1} & \tilde{x}_{n 2} & \cdots & \cdots & \tilde{x}_{n n}
\end{array}\right] \\
& \tilde{x}_{i j}=\frac{\tilde{z}_{i j}}{r}=\left(\frac{z_{a^{i}}}{r}, \frac{z_{b_{i j}^{i}}}{r}, \frac{z_{c_{i j}}}{r}, \frac{z_{d_{i j}}}{r} ; H_{1}\left(z_{i j}^{U}\right), H_{2}\left(z_{i j}^{U}\right)\right),\left(\frac{z_{e^{i}}}{r}, \frac{z_{f_{i j}}}{r}, \frac{z_{g_{i j}}}{r}, \frac{z_{h_{i j}}}{r} ; H_{1}\left(z_{i j}^{L}\right), H_{2}\left(z_{i j}^{L}\right)\right) \\
& r=\max \left(\max _{1 \leq i \leq n} \sum_{j=1}^{n} Z_{d_{\imath \jmath}}, \max _{1 \leq i \leq n} \sum_{j=1}^{n} Z_{d_{\imath \jmath}}\right)
\end{aligned}
$$

The third step is to define the total relation matrix as follows

$$
X_{\dot{a}}=\left[\begin{array}{ccccc}
0 & a_{12}^{\prime} & \cdots & \cdots & a_{1 n}^{\prime} \\
a_{21}^{\prime} & 0 & \cdots & \cdots & a_{2 n}^{\prime} \\
\vdots & \vdots & \ddots & \cdots & \cdots \\
\vdots & \vdots & \vdots & \ddots & \vdots \\
a_{n 1}^{\prime} & a_{n 2}^{\prime} & \cdots & \cdots & 0
\end{array}\right], \ldots, X_{h}=\left[\begin{array}{ccccc}
0 & h_{12}^{\prime} & \cdots & \cdots & h_{1 n}^{\prime} \\
h_{21}^{\prime} & 0 & \cdots & \cdots & h_{2 n}^{\prime} \\
\vdots & \vdots & \ddots & \cdots & \cdots \\
\vdots & \vdots & \vdots & \ddots & \vdots \\
h_{n 1}^{\prime} & h_{n 2}^{\prime} & \cdots & \cdots & 0
\end{array}\right]
$$


Comparative Analysis of Investor Sentiment with Weather Conditions Using Interval Type 2 Fuzzy Hybrid Decision Making and Regression Methods: Evidence from Chinese Stock Markets

$$
\begin{aligned}
& \tilde{T}=\left[\begin{array}{ccccc}
\tilde{t}_{11} & \tilde{t}_{12} & \cdots & \cdots & \tilde{t}_{1 n} \\
\tilde{t}_{21} & \tilde{t}_{22} & \cdots & \cdots & \tilde{t}_{2 n} \\
\vdots & \vdots & \ddots & \cdots & \cdots \\
\vdots & \vdots & \vdots & \ddots & \vdots \\
\tilde{t}_{n 1} & \tilde{t}_{n 2} & \cdots & \cdots & \tilde{t}_{n n}
\end{array}\right] \\
& \tilde{t}_{i j}=\left(a^{\prime \prime}{ }_{i j}, b^{\prime \prime}{ }_{i j}, c^{\prime \prime}{ }_{i j}, d^{\prime \prime}{ }_{i j} ; H_{1}\left(\tilde{t}_{i j}{ }^{U}\right), H_{2}\left(\tilde{t}_{i j}{ }^{U}\right)\right),\left(e^{\prime \prime}{ }_{i j}, f^{\prime \prime}{ }_{i j}, g^{\prime \prime}{ }_{i j}, h^{\prime \prime}{ }_{i j} ; H_{1}\left(\tilde{t}_{i j}{ }^{L}\right), H_{2}\left(\tilde{t}_{i j}{ }^{L}\right)\right) \\
& {\left[a^{\prime \prime}{ }_{i j}\right]=X_{\dot{a}} \times\left(I-X_{\dot{a}}\right)^{-1}, \ldots ., \quad\left[h^{\prime \prime}{ }_{i j}\right]=X_{\hat{h}} \times\left(I-X_{\hat{h}}\right)^{-1}}
\end{aligned}
$$

The following step is to compute the defuzzied values of total relation matrix. For that, the defuzzification method of Kahraman et al. (2014) is selected as

$D e f_{T}=\frac{\frac{\left(u_{U}-l_{U}\right)+\left(\beta_{U} \times m_{1 U}-l_{U}\right)+\left(\alpha_{U} \times m_{2 U}-l_{U}\right)}{4}+l_{U}+\left[\frac{\left(u_{L}-l_{L}\right)+\left(\beta_{L} \times m_{1 L}-l_{L}\right)+\left(\alpha_{L} \times m_{2 L}-l_{L}\right)}{4}+l_{L}\right]}{2}$

Where $\alpha$ and $\beta$ are the maximum membership degrees of the lower membership function, and $u_{U}, l_{U}$ are is the largest and least possible values of the upper membership function. However, $m_{1 U}$ and $m_{2 U}$ are the consecutive elements of the upper membership function, $u_{L}, l_{L}$ are the largest and least possible values of the lower membership function. Also, $m_{1 L}$ and $m_{2 L}$ are other elements of the lower membership function.

$$
\begin{gathered}
D e f_{T}=T=\left[t_{i j}\right]_{n \times n}, i, j=1,2, \ldots, n \\
\widetilde{D}_{i}^{\text {def }}=r=\left[\sum_{j=1}^{n} t_{i j}\right]_{n \times 1}=\left(r_{i}\right)_{n \times 1}=\left(r_{1}, \ldots, r_{i}, \ldots, r_{n}\right) \\
{\tilde{R}_{i}}^{\text {def }}=y=\left[\sum_{i=1}^{n} t_{i j}\right]_{1 \times n}^{\prime}=\left(y_{j}\right)_{1 \times n}^{\prime}=\left(y_{1}, \ldots, y_{i}, \ldots, y_{n}\right)
\end{gathered}
$$

$\left(\widetilde{D}_{i}+\tilde{R}_{i}\right)^{\text {def }}$ defines the weights of criteria, and $\left(\widetilde{D}_{i}-\widetilde{R}_{i}\right)^{\text {def }}$ shows the impact and relation degrees among the criteria.

Technique for Order Preference by Similarity to Ideal Solution, abbreviated as TOPSIS, is firstly used in 1980s for ranking the elements in the finite set according to the maximized and minimized distances from the ideal solutions (Hwang and Yoon, 1981). Computation process of this method is summarized as the following.

The first step is to normalize the values with the vector normalization

where $\mathrm{i}=1,2,3, \ldots . \mathrm{m}$, and $\mathrm{j}=1,2,3, \ldots \mathrm{n}$

$$
r_{i j}=\frac{X_{i j}}{\sqrt{\sum_{i=1}^{m} X_{i j}^{2}}}
$$

DOI: 10.24818/18423264/54.3.20.16 
Hsiao-Fen Hsiao, Chunying Xia, Serhat Yüksel, Hasan Dinçer

The second step is to weight the values of decision matrix as

$$
v_{i j}=w_{i j} \times r_{i j}
$$

The third step is to compute the values of positive $\left(A^{+}\right)$and negative $\left(A^{-}\right)$ ideal solutions for the benefit and cost criteria.

$$
\begin{gathered}
A^{+}=\left\{v_{1 j}, v_{2 j}, \ldots, v_{m j}\right\}=\left\{\max v_{1 j} \text { for } \forall j \in n\right\} \\
A^{-}=\left\{v_{1 j}, v_{2 j}, \ldots, v_{m j}\right\}=\left\{\min v_{1 j} \text { for } \forall j \in n\right\}
\end{gathered}
$$

The following step is to calculate the distances to the best $\left(D_{i}^{+}\right)$and the worst $\left(D_{i}^{-}\right)$values

$$
\begin{aligned}
& D_{i}^{+}=\sqrt{\sum_{j=1}^{n}\left(v_{i j}-A_{j}^{+}\right)^{2}} \\
& D_{i}^{-}=\sqrt{\sum_{j=1}^{n}\left(v_{i j}-A_{j}^{-}\right)^{2}}
\end{aligned}
$$

The fifth step is to compute the relative closeness degrees are calculated to provide the final results

$$
R C_{i}=\frac{D_{i}^{-}}{D_{i}^{+}+D_{i}^{-}}
$$

Where $R C_{i}$ is the values between 0 and 1 .

The first step of the study was to test for collinearity with the variance inflation factor (VIF) test to eliminate multicollinearity interference.

The second step was to integrate the stock data from all five cities and explore the relationship between local weather patterns and stock market returns through multiple linear regression analyses. After constructing the model, we found that the institutional investor shareholding ratio and gross regional product values were not strong enough in and of themselves to explain the return rates, and for this reason, the following linear regression equation was formulated (30):

$$
\begin{gathered}
\text { Return }_{t}=\alpha+\beta_{1} \text { Cloud }_{t}+\beta_{2} \text { Change }_{t}+\beta_{3} \text { Lnvalue }_{t}+\beta_{4} \text { Lndeal }_{t}+\beta_{5} \text { Aver }_{t} \\
+\varepsilon_{t}
\end{gathered}
$$

The third step was to construct the following multi-linear regression model (31) using weather variables and control variables from the various cities to regress A-share stock market return rates and explore their correlation.

$$
\begin{aligned}
\text { Return }_{i, t}=\alpha & +\beta_{1} \text { Cloud }_{i, t}+\beta_{2} \text { Change }_{i, t}+\beta_{3} \text { Lnvalue }_{i, t} \\
& +\beta_{4} \text { Invest }_{i, t}+\beta_{5} \text { Lndeal }_{i, t}+\beta_{6} \text { Aver }_{i, t}+\beta_{7} \text { GDP }_{i, t}+\varepsilon_{i, t}(31) \\
& \text { i: five cities }
\end{aligned}
$$

The fourth step was to separate all companies based on the board where they are listed: the main board and the SME board/the growth enterprise market (GEM) board. Most of the companies listed on the main board are large, established companies with large-scale capitalization and consistent profitability. We constructed the linear regression model (32) for two types of company 
Comparative Analysis of Investor Sentiment with Weather Conditions Using Interval Type 2 Fuzzy Hybrid Decision Making and Regression Methods: Evidence from Chinese Stock Markets

characteristics. Using the weather variable and control variable, we performed a regression analysis on the stock market return rate.

$$
\begin{aligned}
\text { Return }_{j, t}=\alpha+ & \beta_{1} \text { Cloud }_{j, t}+\beta_{2} \text { Change }_{j, t}+\beta_{3} \text { Lnvalue }_{j, t} \\
& +\beta_{4} \text { Invest }_{j, t}+\beta_{5} \text { Lndeal }_{j, t}+\beta_{6} \text { Aver }_{j, t}+\beta_{7} G D P_{j, t}+\varepsilon_{j, t}(32)
\end{aligned}
$$

$\mathrm{j}$ : the main board and the SME board/the growth enterprise market (GEM) board.

The fifth step was robustness testing, using weather variables and control variables to perform regressions on the B-share market data to verify whether the results in this research are only applicable to the A-share market.

\section{An Analysis on Chinese Stock Market}

The present study assesses the impact of local weather on the return rates of local stock markets. Local weather is used as the explanatory variable, and the stock market return rate is the explained variable. This paper uses the local cloud coverage as the proxy indicator of local weather. We selected company size, transaction volume, turnover rate, institutional shareholding ratio, local average turnover rate, and local gross domestic product (GDP) as control variables. The definitions of the explanatory variable and the explained variable are shown in Table 1.

Table 1. Variable Definitions

\begin{tabular}{|c|c|c|}
\hline Variable Name & Symbol & Definition \\
\hline $\begin{array}{c}\text { Return Rate } \\
\text { (V1) }\end{array}$ & Return & $\begin{array}{c}\text { (Today's closing price/Yesterday's closing price }-1 \\
\text { ) } \times 100 \%\end{array}$ \\
\hline $\begin{array}{c}\text { Cloud Coverage } \\
\text { (V2) }\end{array}$ & Clouds & The day's sunlight. Little cloud coverage and strong \\
sunlight.
\end{tabular}

DOI: 10.24818/18423264/54.3.20.16 
Hsiao-Fen Hsiao, Chunying Xia, Serhat Yüksel, Hasan Dinçer

\begin{tabular}{|c|c|c|}
\hline $\begin{array}{c}\text { Gross Regional } \\
\text { Product (V8) }\end{array}$ & GDP & $\begin{array}{c}\text { The gross regional product index refers to the relative } \\
\text { number of trends and the extent of the GDP over a } \\
\text { given time period. (The index is calculated based on the } \\
\text { previous year at a constant price.) }\end{array}$ \\
\hline
\end{tabular}

In Table 1, the larger the company, the greater the influence. Large-scale companies are attractive to investors, resulting in improved stock liquidity, which in turn affects the stock price and the return rates. Cloud coverage means the sun is shining, and only a few clouds are present in the sky. Little cloud coverage makes investors feel refreshed and clear-headed, and they are more optimistic about the stock market. They tend to invest in stocks, increasing the stock return rate and the turnover ratio. Turnover ratio represents a certain degree of stock liquidity and affects the rate of return. The proportion of institutional ownership is the institutional shareholding ratio that to a certain extent shows the optimism about the stock market. Trading volume is negatively correlated with liquidity, thus affecting the rate of return. The turnover average is the total local average turnover rate, which represents the stock-flow of the day in a certain locality, and thus affects the return rate. The gross regional product reflects the trends and extent of growth of the GDP over a certain period of time in a certain locality. The higher the local GDP, the easier it is to generate stock trading, which has an impact on the rate of return.

This paper takes the daily stock data of A-listed stocks from five cities, Beijing, Shanghai, Shenzhen, Hangzhou, and Suzhou, and uses them as research samples. R-studio and Microsoft Excel software were utilized to explore the impact of local weather on the stock market return rate. This research was conducted from January 1, 2011 to December 31, 2017. A total of 1,075 publicly listed companies are included in the selected samples, and a total of 1,021,481 data sets were obtained. A total of 309,359 sets of sample data are taken from Beijing; 258,739 sets are from Shanghai; 271,873 sets are from Shenzhen; 116,332 sets are from Hangzhou; and 65,060 sets are from Suzhou.

The institutional investor ratio data that is used for this research comes from the Resset database; the GDP index comes from the National Bureau of Statistics (www.stats.gov.cn); and other stock market data comes from the Taiwan Economic Journal Southeast Asia financial database. Local weather data comes from Weather Underground (The Weather Company, an IBM service) (www.wunderground.com), which does not directly provide cloud coverage information but instead discloses weather conditions related to cloud coverage such as clear, partly cloudy, overcast, and other descriptions. Values are assigned ranging from 1 to 7.5 , which are converted to represent different levels of cloud coverage: 1 - clear; 2 - clear to partly cloudy; 2.5 - partly cloudy; 3 - cloudy (or rainy); 4 - Overcast (or light rain, light snow); 4.5 - light to moderate rain, showers, thunderstorms, sleet, or light to moderate snow; 5 - moderate rain (or fog or 
Comparative Analysis of Investor Sentiment with Weather Conditions Using Interval Type 2 Fuzzy Hybrid Decision Making and Regression Methods: Evidence from Chinese Stock Markets

moderate snow); 5.5 - medium to heavy rain; 6 - heavy rain; 6.5 - rainstorms; 7 storms; and 7.5 - heavy rain.

Integrated decision-making approach with two stages including IT 2 fuzzy DEMATEL and TOPSIS methods is used respectively for evaluating the performance of stock markets in the selected provinces of China. For this purpose, DEMATEL based on IT2 fuzzy sets is applied for weighting the variables of investor sentiment with respect to the weather conditions, and then TOPSIS is used for ranking the stock market performances by the provinces of China. For that, the mean values of selected provinces are considered to measure the overall performance of stock markets due to the weather effects.

Details of two stage analysis are given below

Stage 1: Weight the variables with IT2 fuzzy DEMATEL. 8 variables of investor sentiment by considering the weather conditions are defined as seen in Table 1. Three decision makers provide their linguistic evaluations for constructing the direct relation matrix. The evaluations are converted into the trapezoidal fuzzy numbers to create the matrix based on IT2 fuzzy sets.In the following steps, normalization and defuzzification processes are applied according to the steps of IT2 fuzzy DEMATEL and the final matrix and weighting results are provided in Table 2.

Table 2. Final relation matrix

\begin{tabular}{|c|c|c|c|c|c|c|c|c|c|}
\hline & V1 & V2 & V3 & V4 & V5 & V6 & V7 & V8 & Weights \\
\hline V1 & 0.06 & 0.08 & 0.10 & 0.13 & 0.13 & 0.11 & 0.10 & 0.16 & 0.124 \\
\hline V2 & 0.24 & 0.06 & 0.19 & 0.24 & 0.25 & 0.24 & 0.22 & 0.27 & 0.159 \\
\hline V3 & 0.09 & 0.05 & 0.04 & 0.08 & 0.07 & 0.09 & 0.09 & 0.08 & 0.101 \\
\hline V4 & 0.09 & 0.06 & 0.10 & 0.05 & 0.09 & 0.10 & 0.09 & 0.11 & 0.114 \\
\hline V5 & 0.10 & 0.05 & 0.09 & 0.07 & 0.05 & 0.11 & 0.09 & 0.14 & 0.120 \\
\hline V6 & 0.09 & 0.05 & 0.12 & 0.12 & 0.12 & 0.06 & 0.12 & 0.14 & 0.128 \\
\hline V7 & 0.09 & 0.06 & 0.09 & 0.09 & 0.13 & 0.12 & 0.05 & 0.15 & 0.119 \\
\hline V8 & 0.10 & 0.08 & 0.09 & 0.12 & 0.11 & 0.11 & 0.08 & 0.07 & 0.136 \\
\hline
\end{tabular}

The deffuzzified values of total relation matrix are constructed, and then the weighting results of variables are computed by using the sums of rows and columns. According to the results, cloud coverage (V2) is the most important factor while company size (V3) has relatively weakest importance between the criteria. Additionally, the averaged value of the relation matrix is considered as the threshold, and higher value than threshold is assumed that there is an influence on the other item.

Stage 2: Rank the alternatives with TOPSIS. 5 provinces in China named Beijing (alternative 1), Shanghai (alternative 2), Shenzhen (alternative 3), Hangzhou (alternative 4), Suzhou (alternative 5) are selected as the alternative set and their stock market performances are measured based on investor sentiment

DOI: 10.24818/18423264/54.3.20.16 
with the weather conditions. For this purpose, the mean values of variables are used for constructing decision matrix. In the following process, the weighting values provided from IT2 fuzzy DEMATEL are used for weighted decision matrix. At the final step, the values of $\mathrm{Di}+$ and Di- as well as $\mathrm{RCi}$ are computed for ranking alternatives. Table 3 represents the ranking results of 5 provinces in China on the investor sentiment with the weather conditions.

Table 3. The Performance results of alternatives

\begin{tabular}{|c|c|c|c|c|}
\hline Provinces/Variables & Di+ & Di- & RCi & Ranking results \\
\hline Beijing (A1) & 0.054 & 0.011 & 0.163 & 5 \\
\hline Shanghai (A2) & 0.052 & 0.017 & 0.243 & 4 \\
\hline Shenzhen (A3) & 0.039 & 0.030 & 0.434 & 3 \\
\hline Hangzhou (A4) & 0.033 & 0.028 & 0.457 & 2 \\
\hline Suzhou (A5) & 0.009 & 0.055 & 0.855 & 1 \\
\hline
\end{tabular}

According to the final results, Suzhou (alternative 5) is the best performance as Beijing (alternative 1) has the worst ranking results among the alternative set for measuring the stock market performance of the selected provinces in China by considering the investor sentiment with the weather conditions. However, the regression analysis is also applied for robustness check and the results are compared for the coherency of the analysis. In the following section, the results of regression analysis are given in detail.

On the other side, regarding the regression analysis, firstly, descriptive statistics of the variables are calculated. The details are given on Appendix (Table A1). By looking at this table, it can be understood that Beijing has a maximum return rate of $67.22 \%$ while the minimum is $-16.29 \%$; the mean is $0.096 \%$, and the median is $0.04 \%$. The rate of return is biased to the right. The data compiled from the other four cities is roughly the same as that of Beijing. With regard to the mean average, the rate of return in Suzhou is higher than that of the other four cities, which is likely due to its mean turnover rate being higher than those of the other four cities. In terms of sunlight, the average value of Beijing is lower than that of the other four cities, indicating that Beijing's level of sunlight is more ample than that of other cities. This is because of the fact that Beijing is located relatively to the north, with fewer rainy days than the other cities included in this study. In addition, the average market value of publicly listed companies in Beijing is higher than that of other cities because of the concentration of large state-owned enterprises such as PetroChina and Sinopec. There are no major data differences in other control variables among the five cities. After that, collinearity test is performed.

After performing the VIF test, the variance inflation factor did not exceed 5. The correlation between the variables is not obvious. The collinearity can be controlled. The variables have passed the collinearity test. Based on descriptive 
Comparative Analysis of Investor Sentiment with Weather Conditions Using Interval Type 2 Fuzzy Hybrid Decision Making and Regression Methods: Evidence from Chinese Stock Markets

statistics and the VIF test, multiple linear regressions were performed on the data obtained. After performing regression analyses on sunlight in the five cities and their stock market return rates, the "cloud" coefficient remained significantly negative. The significance level of Beijing, Shenzhen, and Suzhou is 1 percent, and the significance level of Shanghai and Hangzhou is 5 percent. That is to say, after considering the "home bias" factor, cloud coverage remained negatively correlated with the stock market return rate, thus validating Hypothesis 2. According to the results of the linear regression equation (3), the "cloud" coefficient of the companies listed on the main board is -0.0134 , and the companies listed on the SME and GEM boards have a "cloud" coefficient of -0.0158 , with a significance level of $1 \%$. This shows that the SME and GEM companies are more sensitive to changes in sunlight than those listed on the main board.

This study explored the linear relationship between the weather variables of five cities and the return rate of China's overall A-share market. For the sake of robustness analysis, the stock return rate of the B-share market was selected for this study, and weather variables were used to conduct the regression. Because of the fact that Beijing and Suzhou have no B-share listed companies, this research only regressed the B-share data from Shanghai, Shenzhen, and Hangzhou. The results are shown in Table 4.

DOI: $10.24818 / 18423264 / 54.3 .20 .16$ 
Hsiao-Fen Hsiao, Chunying Xia, Serhat Yüksel, Hasan Dinçer

Table 4. B-shares, Sunlight and Stock Market Returns Regression Analysis Results

\begin{tabular}{|c|c|c|c|}
\hline & Shanghai & Shenzhen & Hangzhou \\
\hline \multirow{2}{*}{$\mathrm{C}$} & 12.87723 & 24.01123 & $21.30114^{*}$ \\
& $(1.342)$ & $(1.615)$ & $(2.070)$ \\
\hline \multirow{2}{*}{ Cloud } & -0.02995 & -0.10640 & $-0.06983^{*}$ \\
& $(-1.289)$ & $(-1.876)$ & $(-2.124)$ \\
\hline \multirow{2}{*}{ Lnvalue } & 0.08074 & -0.08173 & $-0.14963^{*}$ \\
& $(0.97)$ & $(-0.262)$ & $(-2.368)$ \\
\hline \multirow{2}{*}{ Change } & $0.54591^{* * *}$ & $1.41525^{* * *}$ & $1.14162^{* * *}$ \\
& $(9.634)$ & $(5.686)$ & -0.17470 \\
& -0.12476 & -0.20057 & $(-1.911)$ \\
\hline \multirow{2}{*}{ GDP } & $(-1.458)$ & $(-1.719)$ & -0.43526 \\
& $-0.43758^{* *}$ & -0.59082 & $(-1.748)$ \\
\hline \multirow{2}{*}{ Invest } & $(-2.888)$ & $(-1.215)$ & -0.06971 \\
& -0.03369 & -0.17581 & $(-0.690)$ \\
\hline \multirow{2}{*}{ Lndeal } & $(-0.863)$ & $(-1.79)$ & 0.07223 \\
& $-0.10698^{*}$ & $(0.05006$ & $1.311)$ \\
\hline \multirow{2}{*}{ Aver } & $(-2.518)$ & 1198 & 1704 \\
\hline \multirow{2}{*}{ Obs. } & 6200 & 3.817 & 4.366 \\
\hline R2 $(\%)$ & 2.576 & &
\end{tabular}

Note $: *, * *$, and $* * *$ are at $10 \%, 5 \%$, and $1 \%$ significance levels respectively.

As seen in the results of Table 4, the B-share data returned from the three cities of Shanghai, Shenzhen, and Hangzhou shows that the "cloud" coefficient remains negative, which is consistent with the regression of the A-share market. So, it can be inferred that the effect of sunlight on the stock market return rate does not change based on the change of selected samples. The conclusions drawn above are also applicable to the B-share market. However, because of the small number of samples obtained from B-share stocks, the level of significance is affected to a certain extent with only Hangzhou remaining at $10 \%$.

\section{Conclusions}

In this study, it is aimed to evaluate the local weather effects on investor sentiment as well as returns in the China's stock market. In order to reach this objective, a comparative evaluation is performed by making both econometric analysis and fuzzy logic-based examination. First of all, linear regression analysis is made to the stock returns of China A-shares for the period of 1 January 2011 - 31 December 2017. On the other side, in the second stage, IT2 fuzzy DEMATEL and TOPSIS methods are considered respectively for evaluating the performance of stock markets in the selected provinces of China. 
Comparative Analysis of Investor Sentiment with Weather Conditions Using Interval Type 2 Fuzzy Hybrid Decision Making and Regression Methods: Evidence from Chinese Stock Markets

The results of these two different analyses are quite coherent. According to the results, cloud coverage is defined as the most important factor. However, company size has relatively weakest importance between the criteria. In addition to them, it is also concluded that cloud coverage affects the other variables systematically whereas company size does not influence any variables of investor sentiment with the weather conditions. Nevertheless, gross regional product is the most influenced factor among the variable set.

On the other side, it is also defined that Suzhou is the best performance as Beijing has the worst ranking results among the alternative set for measuring the stock market performance of the selected provinces in China. Furthermore, a robustness check is also performed with the regression analysis compared for the coherency of the analysis. The analysis results demonstrate that the cloud coefficient is negative and significant for Beijing, Shenzhen, and Suzhou. Because two different analyses provide parallel results, it can be understood that they are consistent.

The results demonstrate that investors feel more optimistic about stocks and are more inclined to invest when sunlight is stronger. On the other side, it is also identified that investors are more inclined to invest in local stocks because of home bias and this situation causes increase in the local stock market returns. Hence, it would be appropriate to receive incentives to facilitate investors to trade on the stock exchange in bad weather. As an example, it is important to take measures to reduce the problems of investors' motivation, such as inaccessibility of session rooms and slow delivery of orders.

In the analysis process of this study, both IT2 fuzzy DEMATEL, TOPSIS and regression analysis are taken into consideration. Hence, it is aimed to increase the originality. However, the main limitation of this study is focusing on Chinese stock market. In the future studies, another evaluation can be conducted with different methodology, such as ANP, AHP, MOORA, ELECTRE and VIKOR. On the other side, other approaches in behavioral finance can also be used in the evaluation.

ACKNOWLEDGEMENTS

This study is partly supported by Soft Science Research Project of Fujian Province, China under Grant 2019R0080.

\section{REFERENCES}

[1] Abbas, G., Bashir, U., Wang, S., Zebende, G. F. \&Ishfaq, M. (2019), The Return and Volatility Nexus Among Stock Market and Macroeconomic Fundamentals For China. Physica A: Statistical Mechanics and its Applications, 526, 121025;

DOI: $10.24818 / 18423264 / 54.3 .20 .16$ 
Hsiao-Fen Hsiao, Chunying Xia, Serhat Yüksel, Hasan Dinçer

[2] Baykasoğlu, A. \&Gölcük, İ. (2017), Development of an Interval Type-2 Fuzzy Sets Based Hierarchical MADM Model by Combining DEMATEL and TOPSIS. Expert Systems with Applications, 70, 37-51;

[3] Chen, Z., Lu, M., Ming, X., Zhang, X. \& Zhou, T. (2020), Explore and Evaluate Innovative Value Propositions for Smart Product Service System: A Novel Graphics-Based Rough-Fuzzy DEMATEL Method. Journal of Cleaner Production, 243, 118672;

[4] Hill, R. V., \&Viceisza, A. (2012), A Field Experiment on the Impact of Weather Shocks and Insurance on Risky Investment. Experimental Economics, 15(2), 341-371;

[5] Hou, K., Li, X. \& Zhong, W. (2019), Price Limits and Asymmetry of Price Dynamics-High Frequency Evidence from the Chinese Stock Market. Emerging Markets Finance and Trade, 1-15;

[6] Hwang, C. L.\& Yoon, K. (1981), Methods for Multiple Attribute Decision Making. In Multiple attribute decision making (pp. 58-191). Springer, Berlin, Heidelberg;

[7] Jeng, D. J. F. \& Tzeng, G. H. (2012), Social Influence on the Use of Clinical Decision Support Systems: Revisiting the Unified Theory of Acceptance and Use of Technology by the Fuzzy DEMATEL

Technique. Computers \& Industrial Engineering, 62(3), 819-828;

[8] Kahraman, C., Öztayşi, B., Sarı, İ. U. \& Turanoğlu, E. (2014), Fuzzy Analytic Hierarchy Process with Interval Type-2 Fuzzy Sets. KnowledgeBased Systems, 59, 48-57;

[9] Mendel, J. M., John, R. I. \& Liu, F. L. (2006), Interval Type-2 Fuzzy Logical Systems Made Simple. IEEE Transactions on Fuzzy Systems, 14(6), 808-821;

[10] Patil, S. K. \& Kant, R. (2014), A Hybrid Approach Based on Fuzzy DEMATEL and FMCDM to Predict Success of Knowledge Management Adoption in Supply Chain. Applied Soft Computing, 18, 126-135;

[11] Shi, Y., Tang, Y. R. \& Long, W. (2019), Sentiment Contagion Analysis of Interacting Investors: Evidence from China's Stock Forum. Physica A: Statistical Mechanics and its Applications, 523, 246-259;

[12] Wei, P., Mao, X. \& Chen, X. (2019), Institutional Investors' Attention to Environmental Information, Trading Strategies, and Market Impacts: Evidence from China. Business Strategy and the Environment;

[13] Wen, F., Xiao, J., Xia, X., Chen, B., Xiao, Z. \& Li, J. (2019), Oil Prices and Chinese Stock Market: Nonlinear Causality and Volatility Persistence. Emerging Markets Finance and Trade, 55(6), 1247-1263. 